\title{
Copper(I)-catalyzed tandem reaction: synthesis of 1,4-disubstituted 1,2,3-triazoles from alkyl diacyl peroxides, azidotrimethylsilane, and alkynes
}

\author{
Muhammad Israr ${ }^{1,2}$, Changqing $\mathrm{Ye}^{1,2}$, Munira Taj Muhammad ${ }^{1}$, Yajun $\mathrm{Li}^{1}$ \\ and Hongli Bao*1,2
}

\author{
Full Research Paper \\ Address: \\ ${ }^{1}$ Key Laboratory of Coal to Ethylene Glycol and Its Related \\ Technology, State Key Laboratory of Structural Chemistry, Fujian \\ Institute of Research on the Structure of Matter, Center for Excellence \\ in Molecular Synthesis, Chinese Academy of Sciences, 155 Yangqiao \\ Road West, Fuzhou, Fujian 350002, P. R. China and 2University of \\ Chinese academy of Science (UCAS), Beijing 100190, P. R. China \\ Email: \\ Hongli Bao* - hlbao@fjirsm.ac.cn \\ * Corresponding author

\section{Keywords:} \\ alkyl diacyl peroxides; azidotrimethylsilane; click reaction; copper \\ catalysis; radical; 1,2,3-triazoles
}

\author{
Beilstein J. Org. Chem. 2018, 14, 2916-2922. \\ doi:10.3762/bjoc. 14.270
}

Received: 01 September 2018

Accepted: 07 November 2018

Published: 23 November 2018

This article is part of the thematic issue "Reactive intermediates part I: radicals".

Guest Editor: T. P. Yoon

(C) 2018 Israr et al.; licensee Beilstein-Institut.

License and terms: see end of document.

\begin{abstract}
A copper-catalyzed azide-alkyne cycloaddition (CuAAC) reaction for the synthesis of 1,4-disubstituted 1,2,3-triazoles from alkyl diacyl peroxides, azidotrimethylsilane, and terminal alkynes is reported. The alkyl carboxylic acids is for the first time being used as the alkyl azide precursors in the form of alkyl diacyl peroxides. This method avoids the necessity to handle organic azides, as they are generated in situ, making this protocol operationally simple. The $\mathrm{Cu}(\mathrm{I})$ catalyst not only participates in the alkyl diacyl peroxides decomposition to afford alkyl azides but also catalyzes the subsequent CuAAC reaction to produce the 1,2,3-triazoles.
\end{abstract}

\section{Introduction}

The "click chemistry", coined by K. B. Sharpless in 2001 [1], is a powerful chemical transformation that has rapidly orthogonalized traditional disciplinary boundaries. With the discovery of "click chemistry", new fields have been opened for the research and synthesis of functionalized compounds that have applications in medicinal chemistry, drug discovery, materials chemistry, and as well as in bioconjugates [2-12].
The copper-catalyzed azide-alkyne cycloaddition (CuAAC) reaction [13-21], derived from the Huisgen's 1,3-dipolar cycloaddition of azides and alkynes [22], has conceivably emerged as the premier example of click chemistry. Generally, organic azides are used as the azido source in most of the CuAAC reactions (Scheme 1a) [23]. However, the organic azides with low molecular weight are considered to be unstable moieties that 
(a) previous work:

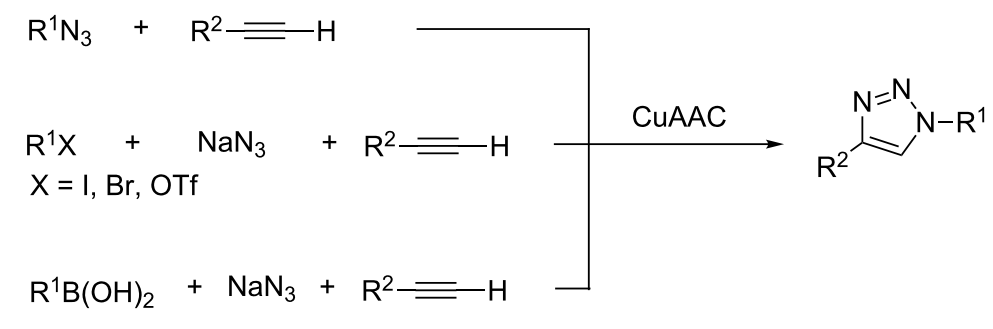

(b) this work:

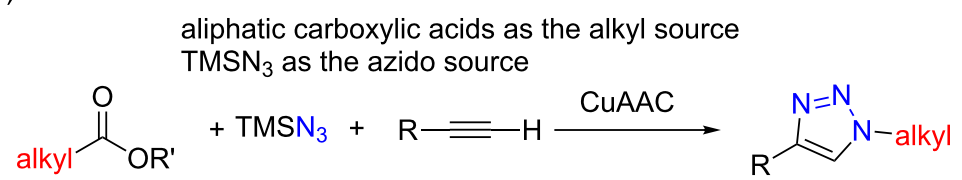

Scheme 1: General methods for the synthesis of triazoles.

can decompose spontaneously, with which the reactions are difficult or dangerous to handle [16]. Thus, a one-pot two-step process for the in situ generation of organic azides is highly required. A frequently used method to in situ generate organic azides is the azidation of organic halides, such as aliphatic halides, vinyl halides, or aromatic halides with sodium azide [24-27]. Organic triflates [28] and organic boronic acids [29-31] can also be used as alternative precursors for organic azides, when reacted with sodium azide.

However, sodium azide is a highly toxic compound and has the potential to explode. Azidotrimethylsilane $\left(\mathrm{TMSN}_{3}\right)$ has been considered as a safer azide source, which actually has been successfully used in the CuAAC reaction directly [32-35], but rarely been used as an azido precursor to enrich the functionality of organic azide source. Moreover, as one of the most commonly appearing compounds in nature, carboxylic acids have rarely been directly used as the organic azide precursors for $\mathrm{CuAAC}$ reactions, considering the frequent involvement of organic halides. Thus, new methods with non or less toxic reagents and enriched organic azide sources for $\mathrm{CuAAC}$ reaction are still highly required.

Herein, we report a novel $\mathrm{CuAAC}$ reaction, using aliphatic carboxylic acids as the alkyl source [36], and $\mathrm{TMSN}_{3}$ as the azide source (Scheme 1b). Because $\mathrm{TMSN}_{3}$ can react with alkynes to form the CuAAC reaction product [32-35], there is one significant challenge of this method that need to be emphasized: how to control the reaction to generate the alkyl azides from aliphatic carboxylic acids and $\mathrm{TMSN}_{3}$, before $\mathrm{TMSN}_{3}$ directly reacting with alkynes.

\section{Results and Discussion}

Based on our unpublished work, we found that alkyl azide has always appeared as a side product when the reaction involved $\mathrm{TMSN}_{3}$ and alkyl diacyl peroxide, easily available compounds derived from aliphatic carboxylic acids. With this information in mind, initially, we started our investigation with phenylacetylene (1a), commercially available lauroyl peroxide (2a), and $\mathrm{TMSN}_{3}$ (Table 1). In a preliminary experiment, the reaction of 1a with $\mathbf{2 a}$ in the presence of $10 \mathrm{~mol} \%$ of $\mathrm{CuCl}$ in THF at $50{ }^{\circ} \mathrm{C}$ afforded 1,4-disubstituted 1,2,3-triazole 3a in $65 \%$ isolated yield (Table 1, entry 1). Surprisingly, under these conditions no $\mathrm{CuAAC}$ product between $\mathrm{TMSN}_{3}$ and phenylacetylene was detected. This result encouraged us to further exploit the optimization of the reaction conditions. Afterwards, the effect of the solvent was also investigated (Table 1, entries 2-8). Dichloromethane could afford the best result and the yield of the desired product 3a could be as high as $97 \%$ (Table 1, entry 2). Other metal salts of copper, such as $\mathrm{Cu}(\mathrm{OAc})_{2}, \mathrm{CuI}$, and $\mathrm{CuBr}$ were then examined and they showed lower catalytic efficiencies than that of $\mathrm{CuCl}$ (Table 1, entries 9-11). Moreover, a reduced amount of the catalyst loading leads to lower yields of product 3a (Table 1, entries 12-14).

With the optimized reaction conditions in hand, the scope of the terminal alkynes was screened and the results are depicted in Scheme 2. First, the reactivity of various substituted terminal arylalkynes was examined. Only 1,4-regioisomeric products were formed with good to excellent yields. Phenylacetylene with an electron-withdrawing bromo-, chloro-, or fluoro substituent afforded the corresponding products $\mathbf{3 h}-\mathbf{n}$ in up to 92\% yield, while phenylacetylenes with electron-donating 
Table 1: Optimization of the reaction conditions ${ }^{a}$

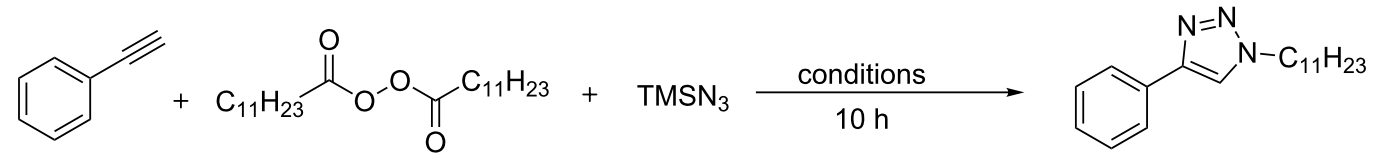

$1 \mathrm{a}$

2a, LPO

$3 a$

\begin{tabular}{|c|c|c|c|}
\hline entry & catalyst (mol \%) & solvent & yield $(\%)^{b}$ \\
\hline 1 & $\mathrm{CuCl}(10)$ & THF & $(65)^{c}$ \\
\hline 2 & $\mathrm{CuCl}(10)$ & $\mathrm{CH}_{2} \mathrm{Cl}_{2}$ & $96(97)^{c}$ \\
\hline 3 & $\mathrm{CuCl}(10)$ & $\mathrm{EtOH}$ & 53 \\
\hline 4 & $\mathrm{CuCl}(10)$ & DMF & 13 \\
\hline 5 & $\mathrm{CuCl}(10)$ & $\mathrm{MeOH}$ & 7 \\
\hline 6 & $\mathrm{CuCl}(10)$ & 1,4-dioxane & trace \\
\hline 7 & $\mathrm{CuCl}(10)$ & $\mathrm{MeCN}$ & trace \\
\hline 8 & $\mathrm{CuCl}(10)$ & acetone & trace \\
\hline 9 & Cul (10) & $\mathrm{CH}_{2} \mathrm{Cl}_{2}$ & 52 \\
\hline 10 & CuBr (10) & $\mathrm{CH}_{2} \mathrm{Cl}_{2}$ & 48 \\
\hline 11 & $\mathrm{Cu}(\mathrm{OAc})_{2}(10)$ & $\mathrm{CH}_{2} \mathrm{Cl}_{2}$ & 64 \\
\hline 12 & $\mathrm{CuCl}(7.5)$ & $\mathrm{CH}_{2} \mathrm{Cl}_{2}$ & 84 \\
\hline 13 & $\mathrm{CuCl}(5)$ & $\mathrm{CH}_{2} \mathrm{Cl}_{2}$ & 70 \\
\hline 14 & $\mathrm{CuCl}(2)$ & $\mathrm{CH}_{2} \mathrm{Cl}_{2}$ & 54 \\
\hline
\end{tabular}

aReaction conditions: $1 \mathrm{a}(0.5 \mathrm{mmol}), 2 \mathrm{a}(0.75 \mathrm{mmol}), \mathrm{TMSN}_{3}(0.75 \mathrm{mmol})$, catalyst ( $\left.\mathrm{mol} \%\right)$, solvent $(2 \mathrm{~mL}), 50{ }^{\circ} \mathrm{C}, 10 \mathrm{~h}$. bYield was determined by ${ }^{1} \mathrm{H}$ NMR analysis. CIsolated yield in parentheses.

groups gave the corresponding products $\mathbf{3 b}-\mathbf{g}$ and $\mathbf{3 0}-\mathbf{q}$ in up to $86 \%$ yield. Instead of a six-membered ring, five-membered heteroaromatics (ethynylthiophenes) have also been used, and afforded the desired products $\mathbf{3 s}$ and $\mathbf{3 t}$ in up to $76 \%$ yield. Terminal aliphatic alkynes were then examined and it was found that they could smoothly deliver the corresponding 1,2,3-triazoles $3 \mathbf{u}-\mathbf{z}$ with high yields.

Furthermore, the scope of the alkyl diacyl peroxides was then studied (Scheme 3). The alkyl diacyl peroxides 2 were synthesized from the corresponding aliphatic carboxylic acids in a single step by DCC-mediated dehydrative condensation with hydrogen peroxide, and were used directly after simple filtration without further treatment; see Supporting Information File 1 for details [37]. The alkyl diacyl peroxides with longchain alkyl groups and methyl-substituted long-chain alkyl groups afforded the corresponding 1,4-disubstituted 1,2,3-triazoles with good to excellent yields (3aa, $\mathbf{3 b b}, \mathbf{3 d d}, \mathbf{3 f f}, \mathbf{3 h h}$, 3ii, and 3II). Remarkably, the chlorodiacyl peroxide also tolerated the reaction conditions to afford chloro-substituted triazole 3ee with good yield. Moreover, alkyl diacyl peroxides bearing a phenyl group, cyclopentyl group, or a cyclohexyl group also afforded good yields (3cc, 3mm, and 3nn). Significantly, diacyl peroxides with cyclic secondary alkanyl and alkenyl groups can

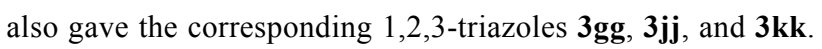

Tertiary alkyl diacyl peroxides are relatively more reactive than primary and secondary alkyl diacyl peroxides, but they are not stable enough for the simple filtration separation at room temperature. Thus, we have not tried the reactions with tertiary alkyl diacyl peroxides.

In order to understand the mechanism of this reaction, we performed a set of experiments (Scheme 4). Firstly a radical capturing reaction was carried out with the addition of a radical trapping reagent (tetramethylpiperdinyloxy, TEMPO) [38,39] to the standard reaction system, no product 3a was obtained; only the radical trapped product 4 was detected by GC-MS (Scheme 4a).

To further investigate this phenomenon, we synthesized a substrate bearing a cyclopropylmethyl moiety, diacyl peroxide $\mathbf{2 p}$, which is a radical-clock $[40,41]$. The reaction of phenylacetylene with the diacyl peroxide $\mathbf{2 p}$ afforded a ring-opened product $3 \mathbf{p p}$ in $88 \%$ yield. This result suggested the engagement of radical species in the reaction (Scheme $4 b$ ).

Based on the previous literature $[16,42,43]$ and the above experimental findings, a possible reaction mechanism is suggested as shown in Scheme 5. In the presence of the $\mathrm{Cu}(\mathrm{I})$ catalyst, alkyl diacyl peroxide decomposes into an alkyl radical, $\mathrm{CO}_{2}$, and 


$$
R^{2}+\mathrm{C}_{11} \mathrm{H}_{23} \stackrel{\mathrm{O}}{\stackrel{\mathrm{H}}{\mathrm{O}}-\mathrm{O}} \prod_{\mathrm{O}}^{\mathrm{C}_{11} \mathrm{H}_{23}}+\mathrm{TMSN}_{3} \frac{\mathrm{CuCl} 10 \mathrm{~mol} \%}{\mathrm{DCM}, 50^{\circ} \mathrm{C}, 10 \mathrm{~h}}
$$

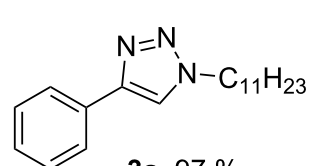

$3 a, 97 \%$

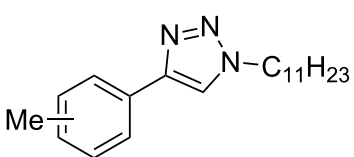

3b, o-Me, $83 \%$ 3c, $p-\mathrm{Me}, 86 \%$

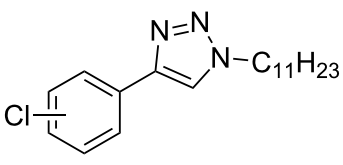

3h, o-Cl, $78 \%$

3i, $m-\mathrm{Cl}, 91 \%$ 3j, $p-\mathrm{Cl}, 92 \%$

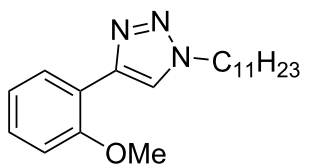

3o, $79 \%$

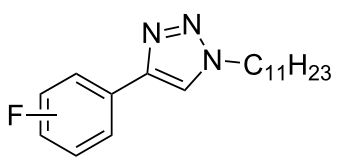

3k, o-F, $76 \%$

3I, $m-\mathrm{F}, 87 \%$

3m, $p-\mathrm{F}, 89 \%$

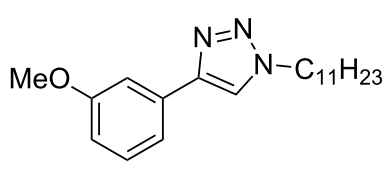

$3 p, 81 \%$

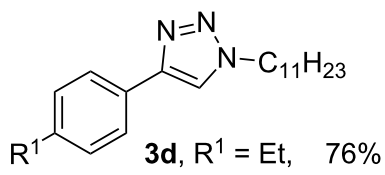

3e, $\mathrm{R}^{1}=n-\mathrm{Pr}, \quad 78 \%$

3f, $\mathrm{R}^{1}=n-\mathrm{Bu}, 85 \%$

$3 \mathrm{~g}, \mathrm{R}^{1}=t-\mathrm{Bu}, \quad 66 \%$

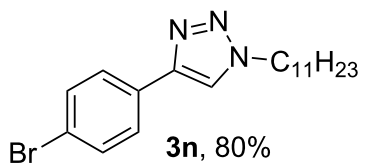

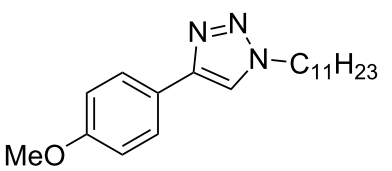

3q, $77 \%$

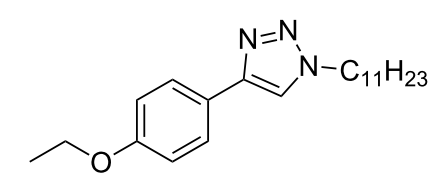

$3 r, 73 \%$

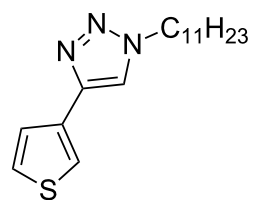

3s, $76 \%$

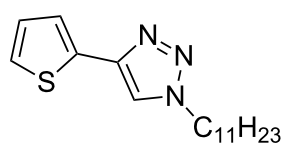

$3 t, 71 \%$

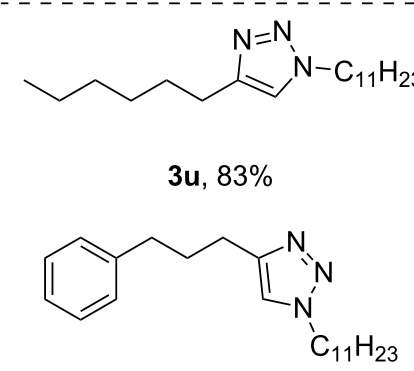

$3 x, 78 \%$<smiles>ClCCCCCCn1cc(CCCCl)nn1</smiles>

$3 v, 68 \%$

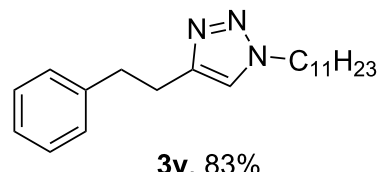<smiles>[14CH3][C+]([14CH3])n1cc(CCCC#N)nn1</smiles>

$3 w, 81 \%$

Scheme 2: Substrate scope of the terminal alkynes. Conditions: $1(0.5 \mathrm{mmol}), 2 \mathrm{a}(0.75 \mathrm{mmol}), \mathrm{TMSN}_{3}(0.75 \mathrm{mmol}), \mathrm{CuCl}(10 \mathrm{~mol} \%), \mathrm{DCM}(2 \mathrm{~mL})$, $50{ }^{\circ} \mathrm{C}, 10 \mathrm{~h}$. Yields of the isolated products are given.

releases a carboxyl-Cu(II) complex, which undergoes a ligand exchange with azidomethylsilane to form azido- $\mathrm{Cu}(\mathrm{II})$ species. The alkyl radical then abstracts the azido moiety from the azido- $\mathrm{Cu}(\mathrm{II})$ species to afford an alkyl azide and the regenerated $\mathrm{Cu}(\mathrm{I})$ catalyst. Then, a conventional $\mathrm{CuAAC}$ process delivers the desired cycloaddition product $\mathbf{3}$.

\section{Conclusion}

In summary, we have established an efficient, ligand- and additive-free CuAAC reaction for the synthesis of 1,4-disubstituted 1,2,3-triazoles directly from a variety of readily accessible substrates such as alkyl diacyl peroxides, azidotrimethylsilane, and terminal alkynes. The alkyl carboxylic acids are for the first 


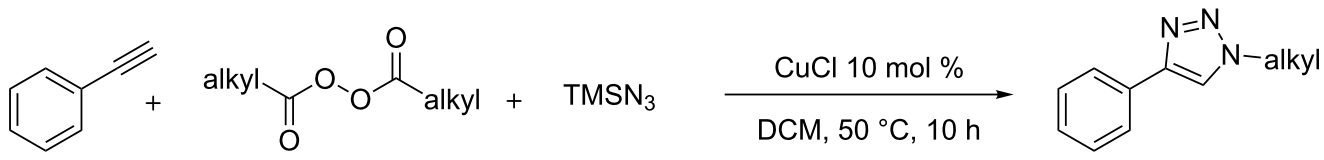

1 a

2

3
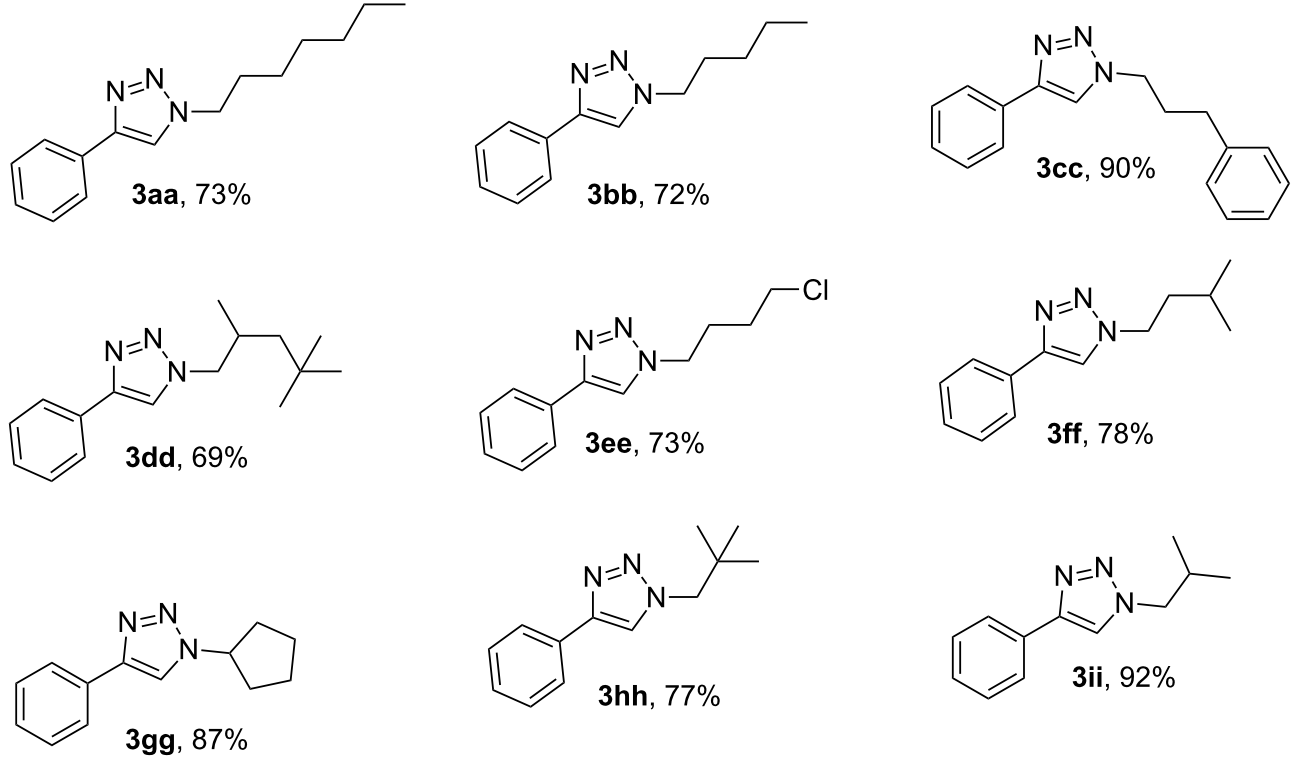<smiles>CCCCOC(=O)c1cc(-c2ccccc2)nn1C1CC=CC1</smiles><smiles>O=S(=O)(O)O[Na]</smiles><smiles>CCC(C)n1cc(-c2ccccc2)nn1</smiles>

$3 \mathrm{jj}, 60 \%$<smiles></smiles><smiles>O=C(O)OC(=O)OCCC1CCCC1</smiles>

Scheme 3: Substrate scope of the alkyl diacyl peroxides. Conditions: $1 \mathrm{a}(0.5 \mathrm{mmol}), 2(0.75 \mathrm{mmol}), \mathrm{TMSN}_{3}(0.75 \mathrm{mmol}), \mathrm{CuCl}(10 \mathrm{~mol} \%), \mathrm{DCM}$ $(2 \mathrm{~mL}), 50^{\circ} \mathrm{C}, 10 \mathrm{~h}$. Yields of the isolated products are given.

(a) addition of 3 equiv of TEMPO

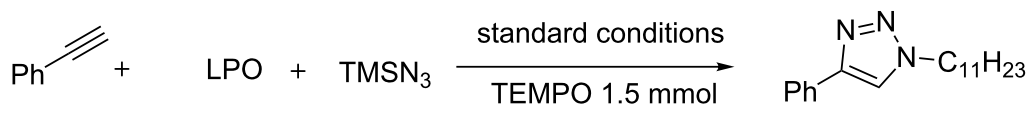

$1 a$

$2 a$

(b) ring-opening experiment<smiles>C#Cc1ccccc1</smiles>

$1 a$<smiles>O=C(CC1CC1)OOC(=O)CC1CC1</smiles>

$2 p$

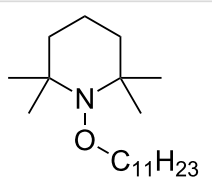

3a, not detected

4, detected by GC-MS<smiles>C=CCCn1cc(-c2ccccc2)nn1</smiles>

$3 p p, 88 \%$

Scheme 4: Preliminary mechanistic studies. 


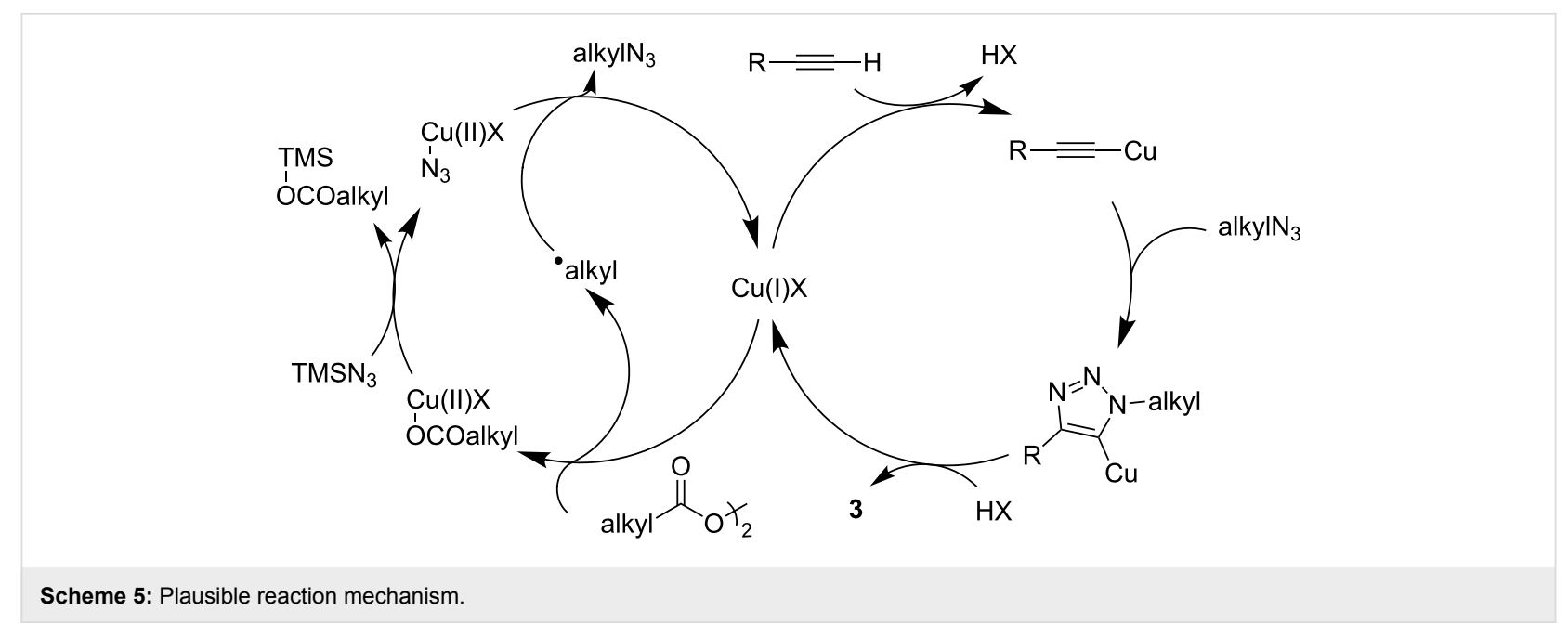

time being used as the alkyl azide precursors in the form of alkyl diacyl peroxides. This method avoids the necessity to handle organic azides, as they are generated in situ, making this protocol operationally simple. This reaction features a wide substrate scope, good functional group tolerance, high yields, and excellent regioselectivity. Most of all, the $\mathrm{Cu}(\mathrm{I})$ catalyst plays two roles in the reaction: decomposes the alkyl diacyl peroxides to afford the alkyl azides and catalyzes the subsequent $\mathrm{CuAAC}$ reaction to produce the 1,2,3-triazoles.

\section{Experimental}

General procedure: To a flame-dried Schlenk tube containing a magnetic stirring bar, terminal alkyne $\mathbf{1}(0.5 \mathrm{mmol})$, diacyl peroxide $2(0.75 \mathrm{mmol}), \mathrm{TMSN}_{3}(90.4 \mathrm{mg}, 0.75 \mathrm{mmol}), \mathrm{CuCl}$ (4.9 mg, $0.05 \mathrm{mmol})$ and $\mathrm{CH}_{2} \mathrm{Cl}_{2}(2 \mathrm{~mL})$ were added, respectively. The reaction mixture was stirred vigorously for $10 \mathrm{~h}$ at $50{ }^{\circ} \mathrm{C}$. Then, the reaction mixture was cooled to room temperature, poured into saturated sodium bicarbonate solution $(25 \mathrm{~mL})$ and extracted with $\mathrm{CH}_{2} \mathrm{Cl}_{2}(3 \times 25 \mathrm{~mL})$. After drying over $\mathrm{MgSO}_{4}$, the solvent was removed under reduced pressure in a rotary evaporator; the residue was purified by column chromatography on silica gel (PE/EA) to afford 3.

\section{Supporting Information}

\section{Supporting Information File 1}

Detailed experimental procedures and characterization data for all new compounds.

[https://www.beilstein-journals.org/bjoc/content/ supplementary/1860-5397-14-270-S1.pdf]

\section{Acknowledgements}

We thank the National Key R\&D Program of China (Grant No. 2017YFA0700103), the NSFC (Grant Nos. 21502191,
21672213), the Strategic Priority Research Program of the Chinese Academy of Sciences (Grant No. XDB20000000), the Haixi Institute of CAS (Grant No. CXZX-2017-P01) and CASTWAS president program of the UCAS for financial support.

\section{References}

1. Kolb, H. C.; Finn, M. G.; Sharpless, K. B. Angew. Chem., Int. Ed. 2001, 40, 2004-2021. doi:10.1002/1521-3773(20010601)40:11<2004::aid-anie2004>3.0.co;25

2. Wang, Q.; Chan, T. R.; Hilgraf, R.; Fokin, V. V.; Sharpless, K. B.; Finn, M. G. J. Am. Chem. Soc. 2003, 125, 3192-3193. doi:10.1021/ja021381e

3. Ustinov, A. V.; Stepanova, I. A.; Dubnyakova, V. V.; Zatsepin, T. S.; Nozhevnikova, E. V.; Korshun, V. A. Russ. J. Bioorg. Chem. 2010, 36, 401-445. doi:10.1134/s1068162010040011

4. Speers, A. E.; Adam, G. C.; Cravatt, B. F. J. Am. Chem. Soc. 2003, 125, 4686-4687. doi:10.1021/ja034490h

5. Nair, D. P.; Podgórski, M.; Chatani, S.; Gong, T.; Xi, W.; Fenoli, C. R.; Bowman, C. N. Chem. Mater. 2014, 26, 724-744. doi:10.1021/cm402180t

6. Moses, J. E.; Moorhouse, A. D. Chem. Soc. Rev. 2007, 36, 1249-1262. doi:10.1039/b613014n

7. Link, A. J.; Tirrell, D. A. J. Am. Chem. Soc. 2003, 125, 11164-11165. doi:10.1021/ja036765z

8. Kolb, H. C.; Sharpless, K. B. Drug Discovery Today 2003, 8, 1128-1137. doi:10.1016/s1359-6446(03)02933-7

9. Hein, C. D.; Liu, X.-M.; Wang, D. Pharm. Res. 2008, 25, 2216-2230. doi:10.1007/s11095-008-9616-1

10. El-Sagheer, A. H.; Brown, T. Chem. Soc. Rev. 2010, 39, 1388-1405. doi:10.1039/b901971p

11. Deiters, A.; Cropp, T. A.; Mukherji, M.; Chin, J. W.; Anderson, J. C.; Schultz, P. G. J. Am. Chem. Soc. 2003, 125, 11782-11783. doi:10.1021/ja0370037

12. Amblard, F.; Cho, J. H.; Schinazi, R. F. Chem. Rev. 2009, 109, 4207-4220. doi:10.1021/cr9001462

13. Tornøe, C. W.; Christensen, C.; Meldal, M. J. Org. Chem. 2002, 67, 3057-3064. doi:10.1021/jo011148j 
14. Rostovtsev, V. V.; Green, L. G.; Fokin, V. V.; Sharpless, K. B. Angew. Chem., Int. Ed. 2002, 41, 2596-2599.

doi:10.1002/1521-3773(20020715)41:14<2596::aid-anie2596>3.0.co;24

15. Meldal, M.; Tornøe, C. W. Chem. Rev. 2008, 108, 2952-3015. doi:10.1021/cr0783479

16. Hein, J. E.; Fokin, V. V. Chem. Soc. Rev. 2010, 39, 1302-1315. doi:10.1039/b904091a

17. Liang, L.; Astruc, D. Coord. Chem. Rev. 2011, 255, 2933-2945. doi:10.1016/j.ccr.2011.06.028

18. Sokolova, N. V.; Nenajdenko, V. G. RSC Adv. 2013, 3, 16212. doi:10.1039/c3ra42482k

19. Haldón, E.; Nicasio, M. C.; Pérez, P. J. Org. Biomol. Chem. 2015, 13, 9528-9550. doi:10.1039/c5ob01457c

20. Wei, F.; Wang, W.; Ma, Y.; Tung, C.-H.; Xu, Z. Chem. Commun. 2016, 52, 14188-14199. doi:10.1039/c6cc06194j

21. Johansson, J. R.; Beke-Somfai, T.; Said Stålsmeden, A.; Kann, N. Chem. Rev. 2016, 116, 14726-14768. doi:10.1021/acs.chemrev.6b00466

22. Huisgen, R. Chapter 1. In 1,3-Dipolar Cycloaddition Chemistry; Padwa, A., Ed.; Wiley: New York, 1984; pp 1-176.

23. Bräse, S.; Banert, K. Organic Azides: Syntheses and Applications; John Wiley \& Sons: Chichester, 2010.

24. Odlo, K.; Høydahl, E. A.; Hansen, T. V. Tetrahedron Lett. 2007, 48, 2097-2099. doi:10.1016/j.tetlet.2007.01.130

25. Liang, X.; Andersen, J.; Bolvig, S. Synlett 2005, 2941-2947. doi:10.1055/s-2005-921887

26. Kacprzak, K. Synlett 2005, 0943-0946. doi:10.1055/s-2005-864809

27. Feldman, A. K.; Colasson, B.; Fokin, V. V. Org. Lett. 2004, 6, 3897-3899. doi:10.1021/ol048859z

28. Quan, Z.-J.; Xu, Q.; Zhang, Z.; Da, Y.-X.; Wang, X.-C. J. Heterocycl. Chem. 2015, 52, 1584-1588. doi:10.1002/jhet.2219

29. Tao, C.-Z.; Cui, X.; Li, J.; Liu, A.-X.; Liu, L.; Guo, Q.-X. Tetrahedron Lett. 2007, 48, 3525-3529. doi:10.1016/j.tetlet.2007.03.107

30. Hao, C.; Zhou, C.; Xie, J.; Zhang, J.; Liu, P.; Dai, B. Chin. J. Chem. 2015, 33, 1317-1320. doi:10.1002/cjoc.201500643

31. Chen, B.; Yang, D.; Fu, N.; Liu, Z.; Li, Y. Synlett 2007, 0278-0282. doi:10.1055/s-2007-968007

32. Partyka, D. V.; Updegraff, J. B.; Zeller, M.; Hunter, A. D.; Gray, T. G. Organometallics 2007, 26, 183-186. doi:10.1021/om0607200

33. Taherpour, A. A.; Kheradmand, K. J. Heterocycl. Chem. 2009, 46, 131-133. doi:10.1002/jhet.36

34. Saha, S.; Kaur, M.; Bera, J. K. Organometallics 2015, 34, 3047-3054. doi:10.1021/acs.organomet.5b00348

35. Carmona, A. T.; Carrión-Jiménez, S.; Pingitore, V.; Moreno-Clavijo, E.; Robina, I.; Moreno-Vargas, A. J. Eur. J. Med. Chem. 2018, 151, 765-776. doi:10.1016/j.ejmech.2018.04.008

36. Kolarovič, A.; Schnürch, M.; Mihovilovic, M. D. J. Org. Chem. 2011, 76, 2613-2618. doi:10.1021/jo1024927

37. Li, Y.; Han, Y.; Xiong, H.; Zhu, N.; Qian, B.; Ye, C.; Kantchev, E. A. B.; Bao, H. Org. Lett. 2016, 18, 392-395. doi:10.1021/acs.orglett.5b03399

38. Moad, G.; Rizzardo, E.; Solomon, D. H. Aust. J. Chem. 1983, 36, 1573-1588. doi:10.1071/ch9831573

39. Dong, X.; Han, Y.; Yan, F.; Liu, Q.; Wang, P.; Chen, K.; Li, Y.; Zhao, Z.; Dong, Y.; Liu, H. Org. Lett. 2016, 18, 3774-3777. doi:10.1021/acs.orglett.6b01787

40. Ge, L.; Li, Y.; Jian, W.; Bao, H. Chem. - Eur. J. 2017, 23, 11767-11770. doi:10.1002/chem.201702385
41. Ye, C.; Li, Y.; Bao, H. Adv. Synth. Catal. 2017, 359, 3720-3724. doi:10.1002/adsc.201700798

42. Zhou, H.; Jian, W.; Qian, B.; Ye, C.; Li, D.; Zhou, J.; Bao, H. Org. Lett. 2017, 19, 6120-6123. doi:10.1021/acs.orglett.7b02982

43. Yuan, Y.-A.; Lu, D.-F.; Chen, Y.-R.; Xu, H. Angew. Chem., Int. Ed. 2016, 55, 534-538. doi:10.1002/anie.201507550

\section{License and Terms}

This is an Open Access article under the terms of the Creative Commons Attribution License

(http://creativecommons.org/licenses/by/4.0). Please note that the reuse, redistribution and reproduction in particular requires that the authors and source are credited.

The license is subject to the Beilstein Journal of Organic Chemistry terms and conditions:

(https://www.beilstein-journals.org/bjoc)

The definitive version of this article is the electronic one which can be found at: $\underline{\text { doi: } 10.3762 / \text { bjoc. } 14.270}$ 